www.jmscr.igmpublication.org

Index Copernicus Value: 79.54

ISSN (e)-2347-176x ISSN (p) 2455-0450

crossrefDOI: https://dx.doi.org/10.18535/jmscr/v7i3.47

\title{
Prevalence of Human Immunodeficiency Virus among Voluntary Blood Donors in a semi-urban setting in West Bengal
}

\author{
Authors \\ Dr Barnik Choudhury ${ }^{1}$, Dr Debjit Chattopadhyay ${ }^{2 *}$ \\ ${ }^{1}$ Associate Professor, Department of Pathology, College of Medicine and J.N.M. Hospital, Kalyani, WB \\ ${ }^{2}$ Assistant Professor, Department of Pathology, College of Medicine and J.N.M. Hospital, Kalyani, WB \\ *Corresponding Author
}

Dr Debjit Chattopadhyay

61, Himangshu Mohan Chakrabarty Road, P.O. ISI, Kolkata 700108, India

Email: debjitchattopadhyay007@gmail.com, Mobile: 9830778808

\begin{abstract}
According to an UNAIDS report from 2018, up to 3 million Indians are infected with Human Immunodeficiency Virus $(H I V)^{l}$. Prevalence of HIV in asymptomatic blood donors represents the window period of HIV infection ${ }^{2}$. Despite the fall in incidence of HIV infection, the fall in incidence to prevalence ratio has slowed down over the last 18 years ${ }^{1}$. All voluntary donors reporting to the blood bank were screened for anti-HIV 1/2 antibodies by using the appropriate enzyme-linked immunosorbent assay. The study was designed for duration of nine years between January 2010 to December 2018. Medical reports of the donors were accessed from the blood bank records and analyzed. A total of 51424 voluntary blood donors were screened, of which 45685 (88.8\%) were males and 5739 (11.2\%) were females. The seroprevalence of HIV was $0.15 \%$.Blood borne transmission of HIV continues to occur despite implementation of highly sensitive screening tests for HIV, suggesting these assays are still not sensitive enough to prevent all infections.
\end{abstract}

Keywords: HIV, ELISA, voluntary blood donors.

\section{Introduction}

The human immunodeficiency virus (HIV) is a retrovirus, an enveloped RNA virus, which is transmissible by the parenteral route. It is found in blood and other body fluids. Once in the bloodstream, the virus primarily infects and replicates in $\mathrm{CD} 4+\mathrm{T}$ lymphocytes. The viral nucleic acid persists by integrating into the host cell DNA ${ }^{3}$.

Several different groups and subtypes (clades) have been identified with some significant antigenic differences; HIV-1 and HIV-2 are the two major distinct virus types and there is significant cross-reactivity between them. HIV-1 is now endemic in many parts of the world, although its incidence and prevalence is low in some regions. HIV-1 group $\mathrm{M}$ is responsible for more than $99 \%$ of the infections worldwide, whereas the prevalence of HIV-2 is mainly restricted to countries in West Africa and India. The appearance of antibody marks the onset and persistence of infection, but not immunity ${ }^{3}$. 
Globally 36.9 million people live withHIV infection, out of which about 3 million live in India ${ }^{1}$. Approximately 940000 people die each year from HIV/AIDS worldwide, out of which about 130000 people died in India in $2017^{1}$. Almost all HIV-infected people will ultimately develop HIV-related disease and AIDS. This progression depends on the type and strain of the virus and certain host characteristics. Factors that may cause faster progression include age less than 5 years, or over 40 years, other infections, and possibly genetic (hereditary) factors. As HIV infection progresses and immunity declines, people become more susceptible to opportunistic infections/neoplasms and ultimately die due to these opportunistic infections and cancers ${ }^{2}$.

According to UNAIDS, 3 million Indians are living with HIV/AIDS ${ }^{1}$. In adults, there is often a long, silent period of HIV infection before the disease progresses to "full blown" AIDS. A person infected with HIV may have no symptoms for up to 10 years or more ${ }^{2}$. This asymptomatic HIV infected population is the source of HIV infected blood despite rigorous donor selection procedures. Thus, the need for mandatory screening for HIV arose.

WHO requires quality-assured screening of all donated blood for transfusion transmissible infections, including HIV. WHO recommends screening to be performed using a highly sensitive and specific anti-HIV-1 + anti-HIV-2 immunoassay or HIV combination antigenantibody immunoassay (EIA/CLIA). The assay should be capable of detecting subtypes specific to the country or region. Screening using a highly sensitive and specific anti-HIV-1 + anti-HIV-2 rapid assay may be performed in laboratories with small throughput, in remote areas or emergency situations $^{3}$. Data on blood safety indicators provided in 2007 by ministries of health to the WHO Global Database on Blood Safety (GDBS) indicate that, of the 155 countries that reported performing $100 \%$ screening for HIV, only 71 screened in a quality-assured manner.
The present study was conducted to determine the prevalence of anti-HIV $1 / 2$ antibodies in voluntary blood donors from a semi-urban setting in and around Kalyani, West Bengal, India and to know the impact of a mandatory screening.

\section{Methods}

A retrospective hospital record-based study was conducted at the blood bank of a teaching hospital in Kalyani, West Bengal, India. The ethics committee of the institute approved the study. Data were collected for a period of 9 years from January 2010 to December 2018. Sera of voluntary blood donors from various localities and of different age groups was screened for HIV antibodies. A total of 51424 blood units were collected and studied. All voluntary blood donors were screened as per WHO criteria for blood donor selection. Five milliliter blood each was collected from subjects into plain, sterile tube. Blood samples were centrifuged and the sera were separated and analyzed. Two kits were used based on WHO recommendation of two different testing strategies involving enzyme-linked immunosorbent assay (ELISA) and/or simple or rapid assays for surveillance. Samples were analyzed for antibodies to HIV $1 / 2$, by ELISA. Any serum found reactive by the first assay was retested using a second assay based on different antigen preparations and/or different test principle using the anti-HIV test. The validity of the test is assured as per the given criterion and the results were computed.

\section{Results}

In the present study, out of a total of 51424 voluntary blood donors, $45685(88.8 \%)$ were males and 5739 (11.2\%) were females which show predominance of males as compared to females for the nine studied years [Table 1]. The prevalence of HIV was $0.15 \%$ among voluntary blood donors in the study population [Table 2]. Other studies show a seroprevalence of $0.35 \%{ }^{4}$ and $0.44 \%$ for HIV. Our seroprevalence is on the lower side probably because we depend on more 
than $95 \%$ voluntary blood donation and our donors coming from a semi-urban setting where risk of exposure to HIV is low.

Sex distribution pattern of voluntary blood donors for HIV prevalence is shown in Table 3 . Prevalence of HIV is more in males as compared to females.

Table 1

\begin{tabular}{|l|c|c|c|}
\hline Year & $\begin{array}{c}\text { Total voluntary } \\
\text { blood donors }\end{array}$ & Male & Female \\
\hline 2010 & 4531 & 4174 & 357 \\
\hline 2011 & 4584 & 4267 & 317 \\
\hline 2012 & 4970 & 4564 & 406 \\
\hline 2013 & 4320 & 4002 & 318 \\
\hline 2014 & 3530 & 3194 & 336 \\
\hline 2015 & 4978 & 4469 & 509 \\
\hline 2016 & 5269 & 4564 & 705 \\
\hline 2017 & 9584 & 8209 & 1375 \\
\hline 2018 & 9658 & 8242 & 1416 \\
\hline Total & 51424 & 45685 & 5739 \\
& & $(88.8 \%)$ & $(11.2 \%)$ \\
\hline
\end{tabular}

Table 2

\begin{tabular}{|l|c|c|c|}
\hline \multirow{2}{*}{ Year } & \multirow{2}{*}{$\begin{array}{c}\text { Number of voluntary } \\
\text { blood donors }\end{array}$} & \multicolumn{2}{|c|}{ Reactive for HIV } \\
\cline { 3 - 4 } & 4531 & Number & Percentage \\
\hline 2010 & 4584 & 6 & 0.11 \\
\hline 2011 & 4970 & 7 & 0.13 \\
\hline 2012 & 4320 & 3 & 0.14 \\
\hline 2013 & 3530 & 4 & 0.07 \\
\hline 2014 & 4978 & 12 & 0.24 \\
\hline 2015 & 5269 & 9 & 0.17 \\
\hline 2016 & 9584 & 18 & 0.19 \\
\hline 2017 & 9658 & 14 & 0.15 \\
\hline 2018 & 51424 & 78 & 0.152 \\
\hline Total & & & \\
\hline
\end{tabular}

Table 3

\begin{tabular}{|l|c|c|}
\hline \multirow{2}{*}{ SEX } & \multicolumn{2}{|c|}{ Reactive for HIV 1/2 } \\
\cline { 2 - 3 } & Number & Percentage \\
\hline Male (45685) & $71(0.155 \%)$ & $91 \%$ \\
\hline Female (5739) & $7(0.122 \%)$ & $9 \%$ \\
\hline Total & 78 & $100 \%$ \\
\hline
\end{tabular}

\section{Acknowledgments}

We would like to acknowledge the help provided by Mr Anik Roy (technical supervisor) and Ms Paromita Gayen (counsellor) of COMJNMH Blood Bank, Kalyani
Sources of support in the form of grants: Nil

\section{References}

1. http://www.unaids.org/sites/default/files/m edia_asset/unaids-data-2018_en.pdf

2. https://www.who.int/hiv/abouthiv/fact_she et_hiv.htm

3. World Health Organization. (2009). Screening donated blood for transfusiontransmissible infections: recommendations Geneva : World Health Organization.

4. Panda M, Kar K: HIV, hepatitis B and C infection status of the blood donors in a blood bank of a tertiary health care centre of Orissa. Indian J Public Health 2008, 52: 43-4.

5. Pallavi P, Ganesh CK, Jayashree K, Manjunath GV. Seroprevalence and trends in transfusion transmitted infections among blood donors in a university hospital blood Bank:a 5 year study. Indian J Hematol Blood Transfus. 2011;27(1):16. doi: 10.1007/s12288-010-0047-x. 